\title{
Assessing the impact of COVID-19 on persons with disabilities: development of a novel survey
}

\author{
Alec Bernard' (1) - Sara Weiss ${ }^{2} \cdot$ Joshua D. Stein ${ }^{2,3,4} \cdot$ Sheryl S. Ulin ${ }^{5} \cdot$ Clive D'Souza $^{5} \cdot$ Anah Salgat $^{6}$. \\ Kate Panzer $^{6} \cdot$ Anne Riddering $^{7} \cdot$ Paul Edwards $^{7} \cdot$ Michelle Meade $^{3,8,9} \cdot$ Michael M. McKee $^{3,6,8}$. \\ Joshua R. Ehrlich ${ }^{2,3,8}$ (1)
}

Received: 18 May 2020/Revised: 5 July 2020 / Accepted: 9 July 2020 / Published online: 23 July 2020

(C) Swiss School of Public Health (SSPH+) 2020

The novel coronavirus (COVID-19) pandemic and accompanying disease-mitigation measures have had an unprecedented global impact. As of the time of writing, the WHO identifies over 10.1 million global cases ( 2.5 million US) and more than 500,000 fatalities (126,000 US) (World Health Organization 2020a, b; Centers for Disease Control 2020).

The WHO defines disability as "any condition of the body or mind that makes it more difficult for the person with the condition to do certain activities and interact with the world around them" (World Health Organization 2020a, b). Even prior to the COVID-19 pandemic, persons with disabilities (PWD) were at greater risk for difficulties

Joshua R. Ehrlich

joshre@med.umich.edu

1 University of Michigan Medical School, Ann Arbor, MI, USA

2 Department of Ophthalmology and Visual Sciences, University of Michigan, 1000 Wall Street, Ann Arbor, MI 48103, USA

3 Institute for Healthcare Policy and Innovation, University of Michigan, 1000 Wall Street, Ann Arbor, MI 48103, USA

4 Department Health Policy and Management, School of Public Health, University of Michigan, Ann Arbor, MI, USA

5 Center for Ergonomics, Department of Industrial and Operations Engineering, University of Michigan, Ann Arbor, MI, USA

6 Department of Family Medicine, University of Michigan, Ann Arbor, MI, USA

7 Department of Ophthalmology, Henry Ford Health System, Detroit, MI, USA

8 Center for Disability Health and Wellness, University of Michigan, 1000 Wall Street, Ann Arbor, MI 48103, USA

9 Department of Physical Medicine and Rehabilitation, University of Michigan, Ann Arbor, MI, USA accessing healthcare, performing instrumental activities of daily living, and maintaining financial well-being (Kweon 2020; Lenze et al. 2001; Garberoglio et al. 2016; Gopinath et al. 2012; World Health Organization 2001, 2011). The impact of the COVID-19 on PWD has not been well described, and it is not known whether the pandemic is disproportionally creating challenges for PWD. Mitigation measures currently in place across the globe are likely to exacerbate many psychological, financial, and day-to-day challenges (Gershman 2020).

Recently, scientific publications and advocacy groups have provided broad recommendations to limit the impact of the pandemic on PWD (Allen and Smith 2020; Senjam 2020; Kessler Foundation 2020; National Association of the Deaf 2020; Rogers 2020). However, there are little data to quantify the impact of the pandemic on PWD, and a thorough review of existing survey instruments demonstrated a clear gap in available instruments to assess the impact on PWD. While long-standing rigorously validated survey instruments like the WHO Model Disability Survey are commonly used in disability survey research, existing instruments may lack content validity since they were not developed with this unprecedented global stressor in mind (World Health Organization 2020a, b). We also reviewed all COVID-19 surveys cataloged on the PhenX Toolkit website (Hamilton et al. 2011); however, there was no single instrument that appeared well targeted to PWD. Accordingly, the decision was made to undertake the development of a novel survey instrument to conduct research specific to the impact of COVID-19 on PWD. Given the highly specific nature of this construct, we believe that this new instrument was needed in order to optimize key measurement properties like content and construct validity (Terwee et al. 2007).

We therefore developed a novel survey instrument, the Coronavirus Disability Survey (COV-DIS), for the purpose of assessing the impact of the COVID-19 pandemic and 
related disease-mitigation measures on PWD. The survey includes items to assess general and psychological health, instrumental activities of daily living, social isolation, financial strain, and information and transportation access.

The 34-item COV-DIS was developed by consensus of a group of experts from the fields of survey research, physical medicine and rehabilitation, family medicine, ophthalmology, and industrial and operations engineering. All experts on the panel had extensive expertise in disability research and/or the clinical care of PWD. The panel drafted and iteratively refined relevant novel survey items. Additionally, based on the review of existing instruments, several items were drawn from other surveys. Items were included from the: CDC COVID-19 Community Survey, Osteoporotic Fractures in Men Study (MROS) and Study of Muscle Mobility and Aging (SOMMA) (Ware and Sherbourne 1992), Understanding America Study (Orwoll et al. 2005), 36-item Short-Form Survey (SF-36) (Hays et al. 1993), and Patient Health Questionnaire-2 (PHQ-2) (Kroenke et al. 2003). Responses to these items can therefore be easily harmonized with data from their parent studies in order to make comparisons between populations. For example, studies from which several of the COV-DIS items were drawn make data publicly available. Data may be directly compared between a study conducted with the COV-DIS and publicly available data (e.g., a national sample in the Understanding America Study). Items from validated instruments such as the SF-36 and the PHQ-2 can also be compared to data from national samples collected in large epidemiological studies (e.g., the Health and Retirement Study or the National Health and Aging Trends Study).

Various COV-DIS items allow for the input of free text to describe the unique experience of respondents. Questions ask respondents to compare current experiences to their experiences prior to becoming aware of the pandemic. This approach may be relevant to the current phase of the pandemic. However, the nature of the pandemic and mitigation measures is likely to change in unpredictable ways. Therefore, it is likely that there will be a need for future users of the COV-DIS to modify question stems in order to specify a timeframe of interest.

We are presently utilizing the COV-DIS to carry out research on the impact of COVID-19 on PWD in southeast Michigan, USA, an area strongly affected by the pandemic (The New York Times 2020). Data will be analyzed to determine the psychometric properties of the COV-DIS and to obtain critical insights into how the COVID-19 pandemic and disease-mitigation measures are affecting the health and well-being of PWD in this region.

The COV-DIS represents a novel instrument to facilitate an urgent research need. However, there are several limitations. Since results of the initial administration of the
COV-DIS are not yet available, the measurement properties of the survey are not known. Additionally, qualitative research was not performed among PWD in order to inform instrument development. Nonetheless, these limitations are due to what we believe was the need to rapidly develop and disseminate a highly relevant survey instrument to enable meaningful research that may benefit the lives of PWD during the COVID-19 pandemic.

In developing and making the COV-DIS freely and publicly available (https://osf.io/p2w9j/.), we hope to promote opportunities for harmonization of data across diverse study populations. Studies using the COV-DIS may have a large impact by providing needed insights to shape datadriven public health and policy decisions that have the potential to optimize the health and well-being of PWD now, during possible future waves of COVID-19 infection, and during other future high-impact societal stressors.

\section{Acknowledgements None.}

Author contributions JRE contributed to the concept of the study. JRE, AB, SW, JS, SU, CD, AS, KP, AR, PE, MM, and MMM contributed to the design of the study. AB and JRE contributed to drafting of the manuscript. All authors contributed to the review and editing of the manuscript.

Funding Funding was provided by an unrestricted grant from the Lighthouse Guild to the University of Michigan Department of Ophthalmology and Visual Sciences. JRE is supported by a grant from the National Institutes of Health (K23EY027848). This work was supported by a grant to $A B$ from the Michigan Institute for Clinical and Health Research with funding provided by the National Institutes of Health (TL1TR002242).

\section{Compliance with ethical standards}

Conflict of interest The authors declare that they have no conflict of interest.

Ethical approval All procedures that will be performed in studies involving human participants will be in accordance with the ethical standards of the institutional committee (University of Michigan Institutional Review Board (IRBMED), HUM00179203) and with the 1964 Declaration of Helsinki and its later amendments or comparable ethical standards.

Informed consent Informed consent will be obtained from all individual participants to be included in the survey. This study currently includes no human subjects.

\section{References}

Allen PM, Smith L (2020) SARS-CoV-2 self-isolation: recommendations for people with a vision impairment. Eye 34:1183-1184. https://doi.org/10.1038/s41433-020-0917-x

Centers for Disease Control (2020) Cases in the U.S. https://www. cdc.gov/coronavirus/2019-ncov/cases-updates/cases-in-us.html. Accessed 30 June 2020 
Garberoglio CL, Cawthon S, Bond M (2016) Deaf people and employment in the United States. Washington, DC: US Department of Education, Office of Special Education Programs, National Deaf Center on Postsecondary Outcomes

Gershman J (2020) A Guide to State Coronavirus Reopenings and Lockdowns. The Wall Street Journal, Dow Jones \& Company www.wsj.com/articles/a-state-by-state-guide-to-coronaviruslockdowns-11584749351. Accessed 8 May 2020

Gopinath B, Schneider J, McMahon CM, Teber E, Leeder SR, Mitchell P (2012) Severity of age-related hearing loss is associated with impaired activities of daily living. Age Ageing 41(2): 195-200

Hamilton et al (2011) The PhenX toolkit: get the most from your measures. Am J Epidemiol 174(3):253-260

Hays RD, Sherbourne CD, Mazel RM (1993) The rand 36-item health survey 1.0. Health Econ 2(3):217-227

Kessler Foundation (2020) COVID-19 and spinal cord injury: minimizing risks for complications. https://kesslerfoundation. org/info/covid-19-and-spinal-cord-injury-minimizing-risks-com plications. Accessed 30 June 2020

Kroenke K, Spitzer RL, Williams JBW (2003) The patient health questionnaire-2: validity of a two-item depression screener. Med Care 41:1284-1292. https://doi.org/10.1097/01.MLR. $0000093487.78664 .3 \mathrm{C}$

Kweon S (2020) Pandemics hit people with disabilities hard. https:// www.iapb.org/news/pandemics-hit-people-with-disabilitieshard/. Accessed 30 June 2020

Lenze EJ, Rogers JC, Martire LM, Mulsant BH, Rollman BL, Dew MA, Reynolds CF III (2001) The association of late-life depression and anxiety with physical disability: a review of the literature and prospectus for future research. Am J Geriatr Psychiatry 9(2):113-135

National Association of the Deaf (2020) COVID-19: deaf and hard of hearing communication access recommendations for the hospital. https://www.nad.org/covid19-communication-access-recsfor-hospital/. Accessed 30 June 2020
Orwoll E, Blank JB, Barrett-Connor E, Cauley J, Cummings S, Ensrud K, McGowan J (2005) Design and baseline characteristics of the osteoporotic fractures in men (MrOS) study-a large observational study of the determinants of fracture in older men. Contemp Clin Trials 26(5):569-585

Rogers L (2020) COVID-19 and blindness: staying safe and how to help. https://www.wsblind.org/blog/2020/3/26/covid-19-andblindness-staying-safe-and-how-to-help. Accessed 30 June 2020

Senjam SS (2020) Impact of COVID-19 pandemic on people living with visual disability. Indian J Ophthalmol 68(7):1367

Terwee CB, Bot SD, de Boer MR, van der Windt DA, Knol DL, Dekker J, Bouter LM, de Vet HC (2007) Quality criteria were proposed for measurement properties of health status questionnaires. J Clin Epidemiol 60(1):34-42

The New York Times (2020) Michigan coronavirus map and case count. https://www.nytimes.com/interactive/2020/us/michigancoronavirus-cases.html. Accessed 30 June 2020

Ware J, Sherbourne C (1992) The MOS 36-item short-form health survey (SF-36): I. Conceptual framework and item selection. Med Care 30(6):473-483

World Health Organization (2001) International classification of functioning, disability and health: ICF. https://apps.who.int/iris/ handle/10665/42407. Accessed 30 June 2020

World Health Organization (2011) World report on disability. Accessed 30 June 2020

World Health Organization (2020a) Model disability survey. In: World Health Organization. https://www.who.int/disabilities/ data/mds/en/. Accessed 30 June 2020

World Health Organization (2020b) Coronavirus. https://www.who. int/emergencies/diseases/novel-coronavirus-2019. Accessed 30 June 2020

Publisher's Note Springer Nature remains neutral with regard to jurisdictional claims in published maps and institutional affiliations. 